\title{
A Statistical Trend Analysis on Area and Production of Jasmine in Andhra Pradesh, India
}

\author{
N. Naga Tejasri ${ }^{1 *}$, N. Vani $^{2}$, N. T. Krishna Kishore ${ }^{1}$ and B. Ramana Murthy ${ }^{3}$
}

${ }^{1}$ Institute of Agribusiness Management, Acharya N. G. Ranga Agricultural University, India

${ }^{2}$ Department of Agriculture Economics, ${ }^{3}$ Department of Agricultue Statistics and Computer

Applications, Sri Venkateswara Agricultural College, Acharya N. G. Ranga Agricultural

University, India

*Corresponding author

\begin{abstract}
A B S T R A C T
Keywords

Jasmine,

Jasminum

grandiflorum

Article Info

Accepted:

25 October 2020

Available Online:

10 November 2020

The present study was carried out to learn the trends in area and production of jasmine in Andhra Pradesh, India for a period of twenty years i.e., from 1998-1999 to 2017-2018. The data was tried to fit in growth models such as linear, compound, inverse, quadratic, cubic, logarithmic, s-curve, growth, power and exponential functions. Inverse curve was found to be the best fitted model based on highest and least RMSE for area and for production. Based on this trend of forecast, the area under next three years under jasmine i.e., for 2019, 2020 and 2021 was 1815.33 ha, 1705.74 ha and 1596.26 ha respectively, while the production of jasmine in the study area would be 19941 MT for 2019, 20332.34 MT for 2020 and 20722.97 MT for 2021. The compound growth rate of area of jasmine was decreasing at a rate of 2.9 per cent CGR whereas production was increasing at a rate of 2.2 per cent.
\end{abstract}

\section{Introduction}

Jasminum grandiflorum is the flowering plant belonging to the Oleaceae family. It is native to tropical and sub-tropical regions of Eurasia. It is also called as "Queen of fragrances" (Ashoka, et al., 2017). This speaks the importance of jasmine. Flower is the economic part of jasmine for which it is commercially grown. It has lots of applications in the medical field. It is used as the cure for hepatitis, cirrhosis, abdominal pain due to severe diarrhoea, etc. Its use is also extended to treat cancer and sedatives to prevent heart stroke. The extracts are used as fortified foods like jasmine tea. On inhalation of jasmine oil, it made the person feel fresh and active by working on central nervous system (Winai et al., 2013).

Jasmine flourished well in high day temperature regions i.e., the temperature should be above $27^{\circ} \mathrm{C}$. The ideal day temperature for jasmine is $27-32^{\circ} \mathrm{C}$ and night temperature is $21-27^{\circ} \mathrm{C}$. The temperature drop to $15-17^{\circ} \mathrm{C}$ for single night would shut down the yield up to 2 weeks (Kenneth and Glenn, 2002). India along with Egypt constitutes for 
95 per cent of the world jasmine production. India exported scented oil extracted from jasmine to England, United States of America, Holland, Sweden, Japan, Norway and European Union (Ashoka et al., 2017). Andhra Pradesh stands third in terms of production after Tamilnadu and Karnataka (APEDA, 2016).

\section{Materials and Methods}

The data regarding area (Hectare) and production (MT) of jasmine in Andhra
Pradesh for a period of 20 years was collected from the Directorate of Economics and Statistics, Government of Andhra Pradesh. The data was examined for the nature of change and degree of relationship in area and production of jasmine in Andhra Pradesh, using SPSS 22 version, various linear and non-linear statistical models were worked out.

The linear and non-linear regression models for the crop characteristics i.e., area and production of jasmine were estimated by fitting the following functions.

\section{Parametric trend Models}

\begin{tabular}{|l|l|}
\hline Model & Functional form \\
\hline Linear function & $\mathrm{y}_{\mathrm{t}}=\mathrm{a}+\mathrm{bt}$ \\
\hline Compound function & $\mathrm{y}_{\mathrm{t}}=\mathrm{ab}^{\mathrm{t}}$ \\
\hline Inverse function & $\mathrm{y}_{\mathrm{t}}=\mathrm{a}+\mathrm{b} / \mathrm{t}$ \\
\hline Quadratic function & $\mathrm{y}_{\mathrm{t}}=\mathrm{a}+\mathrm{bt}+\mathrm{ct}^{2}$ \\
\hline Cubic function & $\mathrm{y}_{\mathrm{t}}=\mathrm{a}+\mathrm{bt}+\mathrm{ct}^{2}+\mathrm{dt}^{3}$ \\
\hline Logarithmic function & $\mathrm{y}_{\mathrm{t}}=\mathrm{a}+\mathrm{b} \ln (\mathrm{t})$ \\
\hline S-Curve function & $\mathrm{y}_{\mathrm{t}}=\mathrm{Exp}(\mathrm{a}+\mathrm{b} / \mathrm{t})\left(\right.$ or) $\ln \left(\mathrm{y}_{\mathrm{t}}\right)=\mathrm{a}+\mathrm{b} / \mathrm{t}$ \\
\hline Growth function & $\mathrm{y}_{\mathrm{t}}=\operatorname{Exp}\left(\mathrm{a}+\mathrm{b}_{\mathrm{t}}\right)($ or $) \ln \left(\mathrm{y}_{\mathrm{t}}\right)=\mathrm{a}+\mathrm{bt}$ \\
\hline Power function & $\mathrm{y}_{\mathrm{t}}=\mathrm{at} \mathrm{t}^{\mathrm{b}}($ or $) \ln \left(\mathrm{y}_{\mathrm{t}}\right)=\ln (\mathrm{a})+\mathrm{b} \ln (\mathrm{t})$ \\
\hline Exponential function & $\mathrm{y}_{\mathrm{t}}=\mathrm{a} \mathrm{e}^{\mathrm{bt}}($ or $) \ln \left(\mathrm{y}_{\mathrm{t}}\right)=\ln (\mathrm{a})+\mathrm{b}_{\mathrm{t}}$ \\
\hline
\end{tabular}

The models fitted to the time series data of area and production were linear, compound, inverse, quadratic, cubic, logarithmic, s-curve, growth, power and exponential functions. To examine the goodness of fit of a model, $\mathrm{R}^{2}$ and Residual Mean Square Error (RMSE) were used. This helped in measuring the accuracy in forecasting by choosing the model among the alternatives (Ramana and Hari, 2018).

$\mathrm{R}^{2}=\mathrm{SS}_{\mathrm{Reg}} / \mathrm{TSS}$

Where

$\mathrm{SS}_{\mathrm{Reg}}=$ Sum of Square due to regression TSS $=$ Total Sum of Square
$\operatorname{RMSE}=\sqrt{\frac{\sum_{t=1}^{n}\left(A_{\bar{t}} F{ }_{t}\right)^{2}}{\mathbf{n}}}$

Where

At is the actual value at time $\mathrm{t}$

$\mathrm{Ft}$ is the forecasted value at time $\mathrm{t}$

The compound growth rate is calculated using compound function.

$\operatorname{CGR}(\%)=(b-1) * 100$

\section{Results and Discussion}

The data presented in Table 1 gave the area and production details over the study period. The compound growth rate of area and 
production was calculated using the compound function. The compound growth rate of area was decreasing at a rate of 2.9 per cent and that of production was increasing at a rate of 2.2 per cent.

Table.1 Area and Production of jasmine in Andhra Pradesh

\begin{tabular}{|c|c|c|}
\hline Year & Area (Ha) & Production (Tonnes) \\
\hline 1999 & 5213 & 2775 \\
\hline 2000 & 5653 & 10755 \\
\hline 2001 & 3878 & 9441 \\
\hline 2002 & 2837 & 15090 \\
\hline 2003 & 5266 & 15499 \\
\hline 2004 & 1698 & 19796 \\
\hline 2005 & 2290 & 21972 \\
\hline 2006 & 2657 & 23386 \\
\hline 2007 & 2634 & 24928 \\
\hline 2008 & 2528 & 26725 \\
\hline 2009 & 2525 & 7962 \\
\hline 2010 & 2141 & 2956 \\
\hline 2011 & 2375 & 2678 \\
\hline 2012 & 2515 & 11987 \\
\hline 2013 & 2307 & 10854 \\
\hline 2014 & 2270 & 11741 \\
\hline 2015 & 2744 & 49861 \\
\hline 2016 & 2363 & 14537 \\
\hline 2017 & 2718 & 8950 \\
\hline 2018 & 2877 & 24220 \\
\hline CGR & $-2.9 \%$ & $2.2 \%$ \\
\hline
\end{tabular}

Table. 2 The parametric values of fitted linear and non-linear models for area of jasmine in Andhra Pradesh

\begin{tabular}{|l|c|c|c|c|c|c|}
\hline \multirow{2}{*}{ Model } & \multicolumn{3}{|c|}{ Coefficients } & \multicolumn{2}{c|}{ Goodness of fit } \\
\hline Linear & $\mathbf{a}$ & $\mathbf{b}$ & $\mathbf{C}$ & $\mathbf{d}$ & \multicolumn{1}{|c|}{$\mathbf{R}^{\mathbf{2}}$} & RMSE \\
\hline Logarithmic & 1693333.51 & -222265.36 & & & $0.34^{* *}$ & 882.52 \\
\hline Inverse & $\mathbf{- 2 1 9 5 5 6 . 7 6}$ & $\mathbf{4 4 6 9 5 0 2 4 6 . 5 7}$ & & & $0.34^{* *}$ & 881.88 \\
\hline Quadratic & 224974.11 & -110.53 & 0.00 & & $0.34^{* *}$ & 882.52 \\
\hline Cubic & 224974.11 & -110.53 & 0.00 & 0.00 & $0.34^{* *}$ & 882.52 \\
\hline Compound & 61278422137521 & 0.97 & & & $0.29^{*}$ & 880.94 \\
& 95000000000000 & & & & \\
\hline Power & 0.00 & & & & & \\
\hline S-Curve & $2.509 E+196$ & -58.42 & & & $0.29^{*}$ & 881.33 \\
\hline Growth & -50.55 & 117489.098 & & & $0.29^{*}$ & 880.77 \\
\hline Exponential & 61278422137521 & -0.03 & & & $0.29^{*}$ & 880.94 \\
\hline & 95000000000000 & & & & & \\
\hline
\end{tabular}


Table.3 Estimated value of area of jasmine in Andhra Pradesh

\begin{tabular}{|l|c|}
\hline Year & Estimated value (ha) \\
\hline $\mathbf{2 0 1 9}$ & 1815.33 \\
\hline $\mathbf{2 0 2 0}$ & 1705.74 \\
\hline $\mathbf{2 0 1 2}$ & 1596.26 \\
\hline
\end{tabular}

Table.4 The parametric values of fitted linear and non-linear models for production of jasmine in Andhra Pradesh

\begin{tabular}{|c|c|c|c|c|c|c|}
\hline \multirow{2}{*}{ Model } & \multicolumn{3}{|c|}{ Coefficients } & \multicolumn{2}{c|}{ Goodness of fit } \\
\cline { 2 - 7 } & $\mathbf{a}$ & $\mathbf{b}$ & $\mathbf{c}$ & $\mathbf{d}$ & $\mathbf{R}^{\mathbf{2}}$ & RMSE \\
\hline Linear & -777480.873 & 394.97 & & & 0.04 & 10441.05 \\
\hline Logarithmic & -6019876.90 & 793632.08 & & & 0.04 & 10440.84 \\
\hline Inverse & $\mathbf{8 0 9 7 8 6 . 0 8}$ & $\mathbf{- 1 5 9 4 6 9 6 5 4 1 . 9 8}$ & & & $\mathbf{0 . 0 5}$ & $\mathbf{1 0 4 4 0 . 6 7}$ \\
\hline Quadratic & -777480.87 & 394.97 & 0.00 & & 0.04 & 10441.05 \\
\hline Cubic & -777480.87 & 394.97 & 0.00 & 0.00 & 0.04 & 10441.05 \\
\hline Compound & $1.361 \mathrm{E}-15$ & 1.02 & & & 0.03 & 10998.69 \\
\hline Power & $6.787 \mathrm{E}-141$ & 43.68 & & & 0.03 & 10998.74 \\
\hline S-Curve & 53.12 & -87776.13 & & & 0.03 & 10998.41 \\
\hline Growth & -34.23 & 0.02 & & & 0.03 & 10998.74 \\
\hline Exponential & $1.361 \mathrm{E}-15$ & 0.02 & & & 0.03 & 10998.74 \\
\hline
\end{tabular}

Table.5 Estimated value of production of jasmine in Andhra Pradesh

\begin{tabular}{|l|l|}
\hline Year & $\begin{array}{l}\text { Estimated value } \\
\text { (MT) }\end{array}$ \\
\hline $\mathbf{2 0 1 9}$ & 19941.33 \\
\hline $\mathbf{2 0 2 0}$ & 20332.34 \\
\hline $\mathbf{2 0 1 2}$ & 20722.97 \\
\hline
\end{tabular}

Fig.1 Depiction of observed area and predicted area

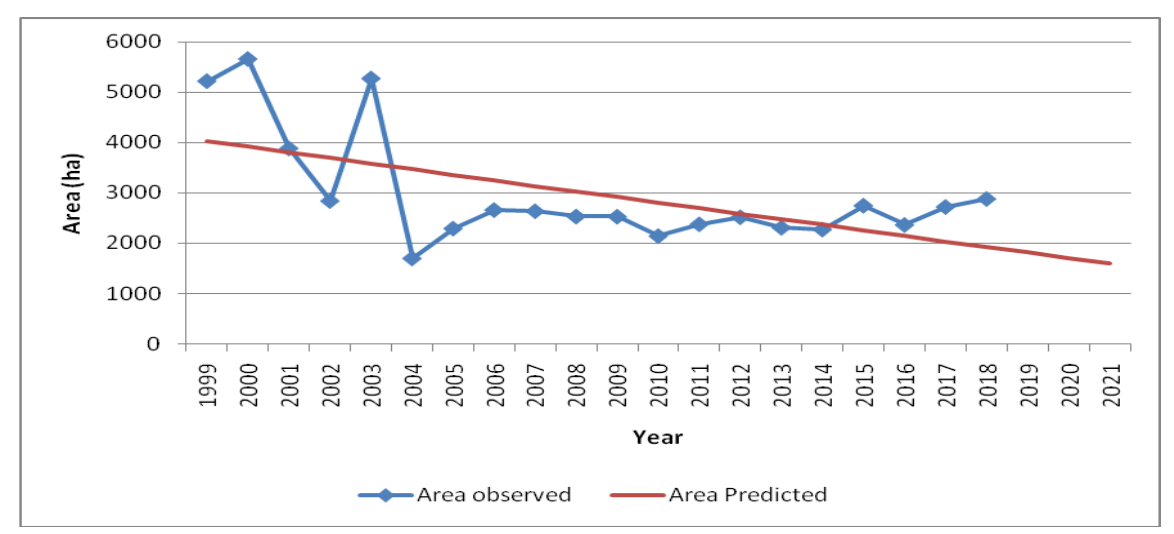


Fig.2 Depiction of observed production and predicted production

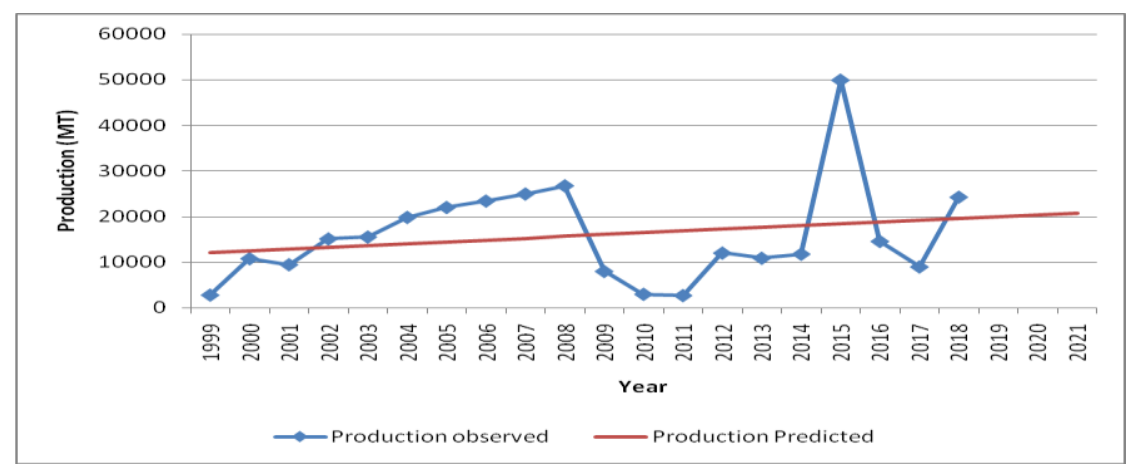

Different linear and non-linear models were employed to study the trend in area and production of jasmine in Andhra Pradesh for the study period. Based on maximum $\mathrm{R}^{2}$ and minimum RMSE values, inverse curve was suitable model for the data and projection of future values of area and production of jasmine in Andhra Pradesh. The results were in conformity with Satheyandrakumar and Chandrashekar (2015) and Pramod (2020).

\section{Trends in area}

Table 2 gave the details of all the models examined to fit the data of area of jasmine in Andhra Pradesh. From the table, it can be observed that inverse model is best fit for the data with maximum $\mathrm{R}^{2}(35 \%)$ and minimum RMSE (880.27). Inverse model was found to be best fit trend for the future projection of area of jasmine. The fitted model was given by

$y_{t}=a+b / t$

Table 3 presented the projected values of jasmine over the next three years i.e., for 2019, 2020 and 2021. The projected value for 2019 was 1815.33 ha, for 2020 was 1705.74 ha and for 2021 it was 1596.26 ha. Figure 1 was the depiction of predicted values for area against observed values for area of jasmine in Andhra Pradesh.

\section{Trends in production}

Maximum $\mathrm{R}^{2}$ value was $5 \%$ and minimum RMSE was 10440.67. These values occurred when the data was fitted with inverse model in Table 4. This has shown that inverse model was the best fit model for the data. The fitted model was given by

$\mathrm{y}_{\mathrm{t}}=\mathrm{a}+\mathrm{b} / \mathrm{t}$

The future projections were displayed in Table 5 which were calculated based on the inverse model. The projected value for the year 2019 was 19941.33 MT, for 2020, it was 20332. 34 MT and for 2021, it was 20722.97 MT.Figure 2 was the depiction of predicted values for production against observed values for prodcution of jasmine in Andhra Pradesh.

In conclusion the compound growth rate for area and production were calculated using compound function. The CGR for area was decreasing at a rate of 2.9 per cent and for production, it was increasing at a rate 2.2 per cent. Inverse model was the best fit model for both area and production of jasmine in Andhra Pradesh. The future values of area and production were projected based on the inverse model. There was decrease in projected values of area from 2019 (1815.33 ha) to 2021 (1705.74 ha) with 2020 (1596.26 ha) being constant. There was an increase in the projected production values with 
19941.33 MT in 2019, 20332.34 MT in 2020 and 20722.97 MT in 2021

\section{References}

Ashoka, N., Shrinivasulu, G. B., Anupama, G., Harshavardhan, M. and Kattimani, K. N. 2017. Economic analysis of production and marketing of Jasmine in Hyderabad - Karnataka region: A case in Koppal district, India. International Journal of Current Microbiology and Applied Sciences. 6(9): 1701-1711.

Kenneth W. Leonhardt and Glenn I. Teves. 2002. Pikake a fragrant - flowered plant for landscapes and lei production. Cooperative Extension Service - College of Tropical Agriculture and Human Resources. OF - 29: 1-4.

Pramod Kumar Das. 2020. A brief study on marigold production in Odisha.
International Journal of Research in Engineering, Science and Management. 3(1): 156-157.

Ramana Murthy, B. and HariBabu, O. 2018.A statistical trend analysis of mango area, production and productivity in Andhra Pradesh.International Journal of Agricultural Statistical Sciences. 14(1): 337-342.

Sathyendra Kumar, A. D. and Chandrashekar, H. M. 2015.Production performance of selected horticultural commodities in Karnataka.International Journal of Management Research and Review. 5(9): 669-675.

WinaiSayowan, Vorasith Siripornpanich, Tapanee Hongratanaworakit and Naiphinich Kotchabhakdi. 2013. The effects of jasmine oil inhalation on brain wave activities and emotions. Journal of Health Research. 27(2): 7377

\section{How to cite this article:}

Naga Tejasri, N., N. Vani, N. T. Krishna Kishore and Ramana Murthy, B. 2020. A Statistical Trend Analysison Area and Production of Jasmine in Andhra Pradesh, India. Int.J.Curr.Microbiol.App.Sci. 9(11): 3746-3751. doi: https://doi.org/10.20546/ijcmas.2020.911.449 